\title{
CONTRIBUTIONS OF PROFESSOR GILBERT STORK IN HETEROCYCLIC CHEMISTRY
}

\author{
Jiro Tsuji \\ Faculty of Engineering, Tokyo Institute of Technology, \\ Meguro, Tokyo 152 Japan
}

\begin{abstract}
Planning to publish a special issue of "Heterocycles" dedicated to Professor Stork on his 65 th birthday in recognition of his great contribution to synthetic organic chemistry, Professor T. Kametani asked me to write about Professor Stork and summarize his scientific contribution, because I am the oldest among nearly 30 Japanese chemists who have been associated with Stork at Columbia as either postdoctral research fellows or graduate students, who form the "Stork group in Japan". In this connection, I know that Frances Hoffman has contributed an excellent article to Aldrichimica Acta $[15,3$ (1982)] to celebrate Stork's 60th birthday. Her article not only chronicles Stork's scientific accomplishments, but also gives a vivid profile of Stork. I thought it would be a futile effort for me to write another one and so I suggest that people should read this article. Here I wish to summarize Stork's scientific accomplishments. But they are enormous in both quality and quantity, and hence I have decided to concentrate on those aspects of Stork's work which have particular relevance to heterocyclic chemistry.
\end{abstract}

It is worth noting that heterocyclic chemistry is where it all began, since Stork's interest in organic synthesis was originally aroused by the alkaloid quinine. His very first paper actually involved a different heterocyclic system, that of furan, specifically the synthesis of a derivative (1) of the then unknown 3,4-diaminofuran, which he thought might be a suitable precursor of Biotin.<smiles>[R6]Nc1cocc1N[N+]([R])([R])O[R]</smiles> 
It is very interesting that Cantharidin (2), which Stork synthesized in 1951, was also a furan derivative. That synthesis is an important milestone in the history of modern organic chemistry because it was the first stereospecific, as well as stereorational, synthesis of a natural product of some complexity.

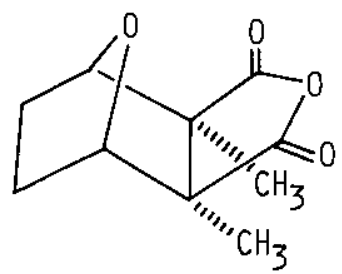

2

In fact, Stork's pioneering work in devising methods for the introduction of stereochemical control in synthesis had started even earlier (1946) with the stereospecific synthesis of another heterocyclic system, the ( \pm )-form of Cincholoipon (3), the name then given to cis-3-ethyl-4piperidineacetic acid, a degradation product of Hydroquinine.<smiles>CC[C@H]1CNCC[C@H]1CC(=O)O</smiles>

3

Some of the methods which Stork's group has contributed to synthesis in general are obviously also useful in heterocyclic construction. The Enamine Alkylation of carbonyl compounds not only can be used starting with pyrrolidones or piperidones, for instance, but the enamines themselves are, of course, made by condensation with heterocyclic amines, such as pyrrolidine, piperidine and morpholine. Stork's total syntheses of Aspidospermine (4) and of Yohimbine (5) are good illustrations of constructions which were greatly simplified by the use of the reaction of enamines with electrophilic olefins. Indeed, the very first two steps in the synthesis of Aspidospermine involve the monoalkylation of butyraldehyde with methyl acrylate, followed by another alkytation with methyl vinyl ketone. The first of these reactions, which can be stopped cleanly at the monoalkylation stage, could not have been carried out by any of the methods available before the advent of the enamine-electrophilic olefin reaction. 


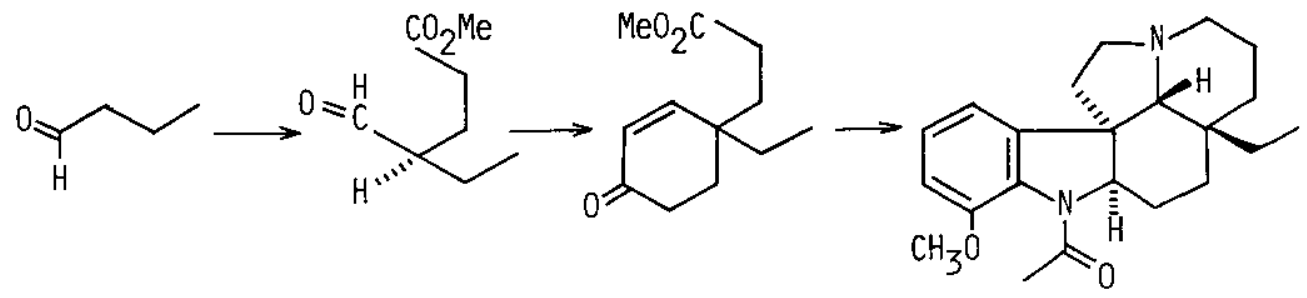

4<smiles>COC(=O)C1=C2CCN(C)CC2CCC1=O</smiles>

5

Obviousiy, the other general methods introduced by the Stork group, such as the regiospecific formation and alkylation of ketone enolates; the alkylation of metalloenamines from imines and from $\mathrm{N}, \mathrm{N}$-dimethylhydrazones; the trapping of enolates as their silyl ethers and their regeneration by cleavage with lithium alkyls are fundamental reactions of modern organic synthesis. They are important in the construction of any system, whether heterocyclic or not. There have been, however, specific contributions to heterocyclic chemistry which should be mentioned in the present context, such as the general synthesis of 4-isoxazolecarboxylic acids (6), the starting materials in a novel cyclohexenone annulation method. Isoxazoles were even used as the starting materials for a new pyridine synthesis. 
<smiles>[R]CO[18O][R16]</smiles><smiles>[R]c1noc([R])c1CC(C)C(C)=O</smiles><smiles>[R]C(=O)c1cc(C)c(C)nc1[R]</smiles>

In the area of structural work related to heterocyclic systems, one may note the early correction of the structures assigned to important reaction products of codeine, the so-called halocodides. While codeine is being mentioned, we should recall the chapter which stork contributed to the "Chemistry of the Alkaloids" series on the mechanistic rationalization of the many remarkable rearrangements of the morphine alkaloids. This was probably the first systematic effort to put the chemistry of a whole class of alkaloids on a consistent and conceptually satisfying basis.

To return now to the use of heterocyclic systems in the synthesis of natural products, one should be allowed to include carbohydrates as heterocyclic compounds. One would then certainly mention the stereospecific synthesis of optically pure Prostaglandin $F_{2}{ }^{\alpha}(8)$ which started with $D$-glucose. The first step actually involved transformation of glucose into another heterocyclic system, namely

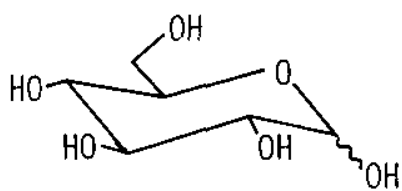

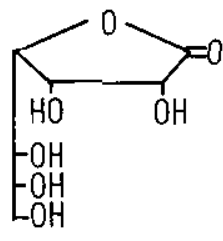

7<smiles>O=C(O)CCC/C=C/C[C@H]1[C@@H](O)C[C@H](O)[C@H]1O</smiles>

8

D-glucoheptono-1,4-lactone (7) which is, after all, a derivative of the 2-furanone system. That synthesis of prostaglandins was one of the earliest examples of the transfer of the C-O asymmetry of a carbohydrate, not only to C-O asymmetry in the target molecule, but to C-C asymmetry as well. In some of Stork's recent work, radical cyclization processes have been used in a new approach to 
the control both of the regiochemistry and the stereochemistry of carbocyclic systems via the temporary formation of 2-alkoxytetrahydrofurans. When these particular heterocyclic systems are constructed on a preexisting ring, they serve to control regio- and stereochemistry at two neighboring centers, as shown tn $\underline{A} \rightarrow \underline{B}$. Stork has recently demonstrated the wide usefulness of this concept by using it to achieve a very simple synthesis of prostaglandins.

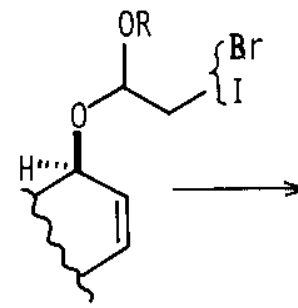

$\underline{A}$

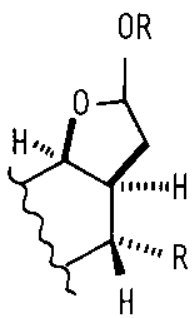

$\underline{B}$

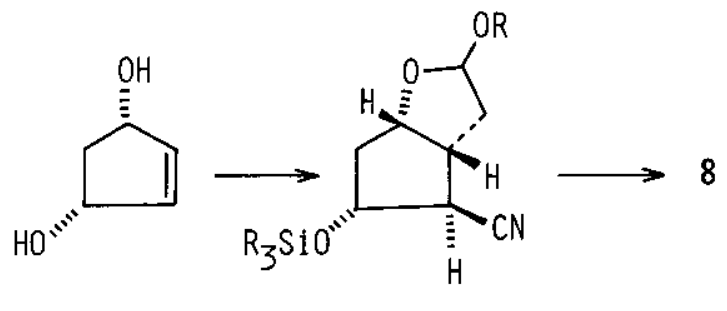

It is interesting that the 2-furanone system figures prominently in an entirely unrelated solution to the long-standing problem of the stereocontrolled construction of polypropionate-related sequences. These are, of course, found in a number of macrolide antibiotics (themselves heterocycles) such as Erythromycin A. The 2-furanone-based scheme is an iterative one which allows the construction, with very high selectivity, of any required stereochemical sequence. Stork claims that one of $j$ ts great virtues is its stereo-rationality, a quality which is often missing from the impressive progress in the use of aldol-like processes toward the same goal. The usefulness and power of the method were recently demonstrated in an efficient synthesis of Erythronolide A (9), the aglycone of Erythromycin A.<smiles>[R][C@H]1OC(=O)[C@@H](O)[C@@H]1C</smiles><smiles>[R][C@]1(CC)C=CC(=O)O1</smiles><smiles>[R][C@]1([2H])OC(=O)[C@@H](O)[C@@H]1C</smiles><smiles>CCCCC</smiles><smiles>[R][C@]1(C)OC(=O)[C@@H](O)[C@H]1C</smiles>

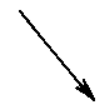<smiles>[R][C@]1([2H])OC(=O)[C@@H](O)[C@@H]1C</smiles>

$\mathrm{H}$

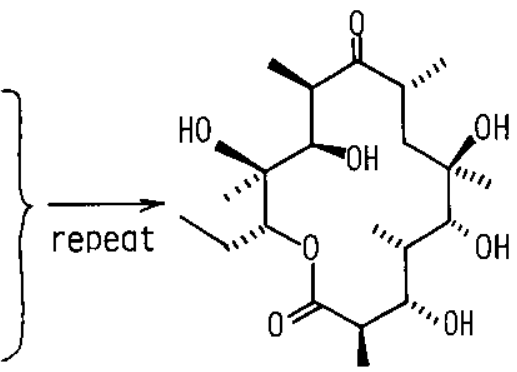


We conclude this survey of some of the more important heterocyclic-related synthetic work from Stork's laboratories by the mention of two important methods of ring formation which are based on the intramolecular opening of oxirane rings. The first one involves the base-catalyzed intramolecular opening of certain cyanoalkyl oxiranes. This synthetic method showed the remarkable feature that it formed four-membered rings in preference to five-membered ones, a result which was shown to be due to a stereoelectronic preference for a linear arrangement of the carbanion center

(H) $(\mathrm{R})$

$(\mathrm{R})(\mathrm{H})$

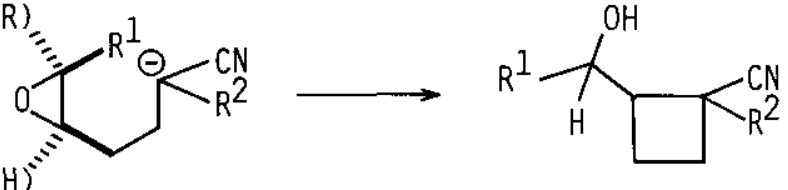

and the oxirane $\mathrm{C}-\mathrm{O}$ bond undergoing displacement. Al though the cyanoepoxide method is quite general and has been used by others even to make large rings, it is most remarkable in being a general non-photochemical method for the formation of cyanocyclobutane derivatives.

Finally, it has recently been shown in Stork's laboratories that it is possible to reverse the tendency to form the smaller of two possible rings, as we have just mentioned above, by making the far end of the oxirane ring adjacent to a double bond. This method promises to be an important one for the formation of highly substituted rings because of its excellent stereoselectivity. It is now being explored in Stork's 1 aboratories in the construction of a number of natural products: a $C / D$ ring system related to the $D$ vitamins and the nerve poison Histrionicotoxin (10) are two notable examples.<smiles>C#C/C=C\C[C@@H]1CCC[C@@]2(CCC[C@@H](O)[C@@H]2/C=C\C#C)N1</smiles>

10<smiles>[R]C1([R])CCC[C@@H]2O[C@@H]2[C@@H]1C=CC</smiles>

$\mathrm{X}=\mathrm{CN}, \mathrm{CO}_{2} \mathrm{R}, \mathrm{COR}$<smiles>C[C@]12CCC[C@@H](O)[C@H]1CCC2=O</smiles>

$\mathrm{HO}$ 